\title{
Towards Decoding Currency Volatilities
}

\author{
D. Johannes Jüttner* \\ Macquarie University, Sydney \\ Wayne Leung \\ Macquarie University, Sydney
}

This study examines on the basis of economic theory the determinants of exchange rate volatilities for a large number of currencies. We relate daily changes in $\operatorname{GARCH}(1,1)$ volatilities of exchange rates to the volatility changes of several of their presumed fundamental economic determinants in the context of a portfolio balance model. The use of high-frequency data limits the choice of the explanatory economic variables that can be included in empirical estimates. The first differences of $\operatorname{GARCH}(1,1)$ volatilities of share and bond price indices reflect portfolio trading decisions in corresponding markets for both assets. In the same vein, first differences of the gold price volatility, as an additional determinant, are related to exchange rate volatilities of two commodity currencies in the sample. The panel data estimates, using the Seemingly Unrelated Regression technique, produce coefficients with the expected signs and statistical significance. The results of our study enhance our understanding of high-frequency currency volatility changes for 19 currencies beyond the purview of announcement effects in the event studies framework (JEL: F31, G154, C22)

Keywords: Exchange rate volatilities, volatility relationships, GARCH modelling

\section{Introduction}

Exchange rates fluctuate significantly even on a daily basis. A great deal

\footnotetext{
* Corresponding author, Tel: 6129449 8194, jjuttner@efs.mq.edu.au. D. J. Jüttner acknowledges sponsorship from the Volkswagenstiftung. An earlier version of the paper was presented at the 2005 conference of the Multinational Finance Society. We thank an anonymous referee for helpful comments.
}

(Multinational Finance Journal, 2009, vol. 13, no. 1/2, pp. 103-134)

(C) Multinational Finance Society, a nonprofit corporation. All rights reserved. DOI: $10.17578 / 13-1 / 2-5$ 
of research has been carried out on the issue of explaining the statistical features of currency volatility. However, to our knowledge very little research is available on the topic of the relationship between the high frequency (daily) exchange rate volatility data with similar volatilities of their presumed economic determinants. Yet, financial markets, firms and policy makers have to make decisions involving currency volatilities on a daily, if not hourly, basis for a range of issues, encompassing the pricing of currency options, the marking-to-market of derivatives, the allocations of asset in portfolios, risk management and currency interventions. While implied volatilities from options are commonly believed to reflect the collective wisdom of the market, they provide no insights into the information sets and processes that market participants apply to this task. Comparatively little is known about how markets form their expectations of foreign currency volatilities and their gyrations over time.

This paper studies the relationship between first differences of the GARCH volatilities of several currencies and the volatilities of their presumed economic determinants through time. Its contribution consists in relating daily changes in currency volatilities to the time-varying volatilities of several economic variables over a period from 1989 to 2003. For the selection of the fundamental economic factors that can be expected to contribute to an explanation of daily volatility changes we rely on a widely supported model of exchange rate determination.

A number of studies examine the relationship between changes in foreign currency volatilities and relevant economic variables in the event study framework. One group of investigations in this line of research examines the impact of scheduled announcements such as the release of the CPI, employment data, current account balance, etc. and non-scheduled news on share index, interest rate and currency volatilities. The studies by Ederington and Lee (1996), DeGennaro and Shrieves (1997), Andersen and Bollerslev (1998), Andersen et al. (2003) and Dominguez and Panthaki (2006) uncover news effects on foreign currency volatilities. The comprehensive investigation of high-frequency volatility processes of Andersen and Bollerslev (1998) reveals that the public information effects of announcements and calendar events are of minor economic importance for daily or lower-level frequency data of the Deutsche-mark-dollar volatility. Andersen et al. (2003) measure directly the impact of scheduled and unscheduled announcements regarding economic fundamentals on exchange rate changes, using high-frequency data (five-minute 
intervals). This approach focuses on the behaviour of exchange rate volatility in the aftermath of news in the event study framework. As expected, the authors find convincing evidence for a role of scheduled and unscheduled announcements moving exchange rates.

A separate class of studies attempts to assess the relationship between official government intervention in foreign currency markets and exchange rate volatility. The evidence by Bonser-Neal and Tanner (1996), Hung (1997) and Dominguez (1998) appears to suggest that there exists, in general, a statistically significant relationship between interventions and currency volatility in the sense that intervention contributes to heightened volatility or dampens it (Kim, Kortian and Sheen, 2000). However, some of the measured correlation may be spurious as heightened volatility frequently prompts interventions by central banks. Moreover, most studies - the exception is Bonser-Neal and Tanner - do not control for the effects of contemporaneously occurring macroeconomic announcements or of other events on volatility. Jansen and De Haan (2005) find evidence of 'verbal intervention' (talking up the currency by central bankers) impacting significantly on conditional EGARCH volatilities.

Relatively few studies are directly devoted to explaining the relationship between changes in volatility of currencies and changes in volatilities of economic/financial variables that theory suggests can be expected to cause, or at least move with, currency volatility changes. The studies with the greatest affinity with our approach relate the volatility of currencies to a number of their presumed fundamental economic influences. Investigations include the work by Kim and Kim (2003) who explore the relationship between the implied volatilities of option on currency futures and corresponding returns on underlying futures returns without attempting to specify an underlying theoretical model. They also examine announcement effects on implied currency volatilities. Devereux and Lane (2003), extending the work by Bayoumi and Eichengreen (1998), explore the relationship between monthly historical currency volatilities by adding internal and external financial factors to optimal currency area variables in their estimation approach.

A study dealing with theory-derived economic determinants of the volatilities of a broad range of exchange rates using high-frequency data over a longer time period appears to be called for. In the next section II we estimate the $\operatorname{GARCH}(1,1)$ volatilities for all variables that are included in the subsequent estimation process. This is followed in III by an analysis of the derivation of the estimation equation from 
reduced-form exchange rate determination models. We convert this relationship into an estimation equation containing daily volatility changes of those variables for which daily data are available. In part IV the estimation results are presented and interpreted. Conclusion are drawn from the estimation outcomes in $\mathrm{V}$.

\section{GARCH (1,1) Estimates of Daily Volatilities}

In order to broaden the range of volatilities of economic variables to exert their influence on, or exhibit a relationship with, exchange rate volatility, we decided to use $\operatorname{GARCH}(1,1)$-generated volatilities for our study. ${ }^{1}$ Alternatively, we could have employed implied volatilities. However, reliable time series data on implied volatilities are only available for instruments for which liquid options markets exist. This would have severely restricted the range of currencies we could have included in our investigation. Our estimation approach encompasses a far greater number of currencies (19) than have been investigated in related studies previously. In addition, we include two minor currencies that happen to be so-called commodity currencies, in our sample, namely the Australian and the Canadian dollars, in order to test their dependence on commodity price volatilities. The exchange rates investigated in the literature range form one currency (Ederington and Lee, 1996) to five (Kim and Kim, 2003); moreover, without exception they are all major currencies with the US dollar as the counterpart. It is therefore less than clear whether the results achieved in the literature can be generalized. By broadening the investigative basis we expose our results, in principle, to a much larger number of potential rejections.

While a definitive verdict on the comparative performance of

1. Our decision to employ GARCH $(1,1)$ estimates of volatilities and not any of the large family of asymmetric GARCH estimation techniques rests on the observation that the distributions of exchange rate changes in general are symmetrical. Our view is also supported by the symmetrical features of the volatility smile obtained from currency options. It appears that the costs and benefits of positive and negative exchange rate changes are distributed equally. Asymmetrical GARCH volatility estimates may be required in event studies dealing with announcements (see Jansen and De Haan, 2005) and they are a feature of equity price changes, reflecting the leverage effect (which is irrelevant for currency changes). Note, share options commonly show a skewed volatility smile. Since neither finance theory nor prior empirical estimates suggests the use of asymmetric GARCH for currencies, interest rates and gold prices, we estimated volatilities in $\operatorname{GARCH}(1,1)$ form. For reason of consistency we employed the same method to the share-index volatilities. 
implied versus time-series volatilities is still outstanding, one obvious disadvantage of GARCH-estimated volatilities concerns their inability to anticipate or capture quickly the volatility-generating effects of periodic macroeconomic public announcements such as inflation and unemployment rates. An option trader armed with a GARCH volatility forecast for the next day when an announcement is scheduled would presumably have to adjust the statistical volatility for the degree of uncertainty associated with the information release. The uncertainty associated with expected announcements may vary over time. The same applies to unscheduled announcements. Adjustments of these kinds are included in implied but not in GARCH volatilities. However, as implied volatilities are derived form actual options prices and prices of the underlying instruments, they will reflect, in addition to pure expectations, liquidity, bid-ask spreads, and the discreteness, rather than continuity, of prices and rates (Jorion, 1995).

The GARCH model requires the joint estimation of a conditional mean equation and a conditional variance relationship. The GARCH $(1,1)$ model has turned out to be the version most favoured by researchers of the group of ARCH approaches.

The mean equation is specified as

$$
r_{t}=\text { constant }+\varepsilon_{t}
$$

where $r_{t}=\ln \left(S_{t} / S_{t-1}\right)$; the term $\varepsilon_{t}$ measures the return surprises.

Variance equation:

$$
\sigma_{t}^{2}=\omega+a \varepsilon_{t-1}^{2}+\beta \sigma_{t-1}^{2}
$$

where $\omega>0 ; \alpha, \beta>0 ; \alpha+\beta<1$ for all variables.

For the majority of variables we obtain 3651 daily return data for each of the seven share and five bond price indices, nineteen currency combinations for seven currencies and gold, which are computed as continuously compounded rates of return from day $t-1$ to day $t$ where for currencies we have $\ln \left(S_{t} / S_{t-1}\right)$, with $S_{t}$ as the exchange rate at day $t^{2}$ Subsequently estimates of equations (1) and (2) generate daily volatility

2. We culled the JPY/CAD and the JPY/GBP exchange rate from the sample due to low turnover in their respective home markets (for turnover data see Bank for International Settlements, March 2002, table E.7). 


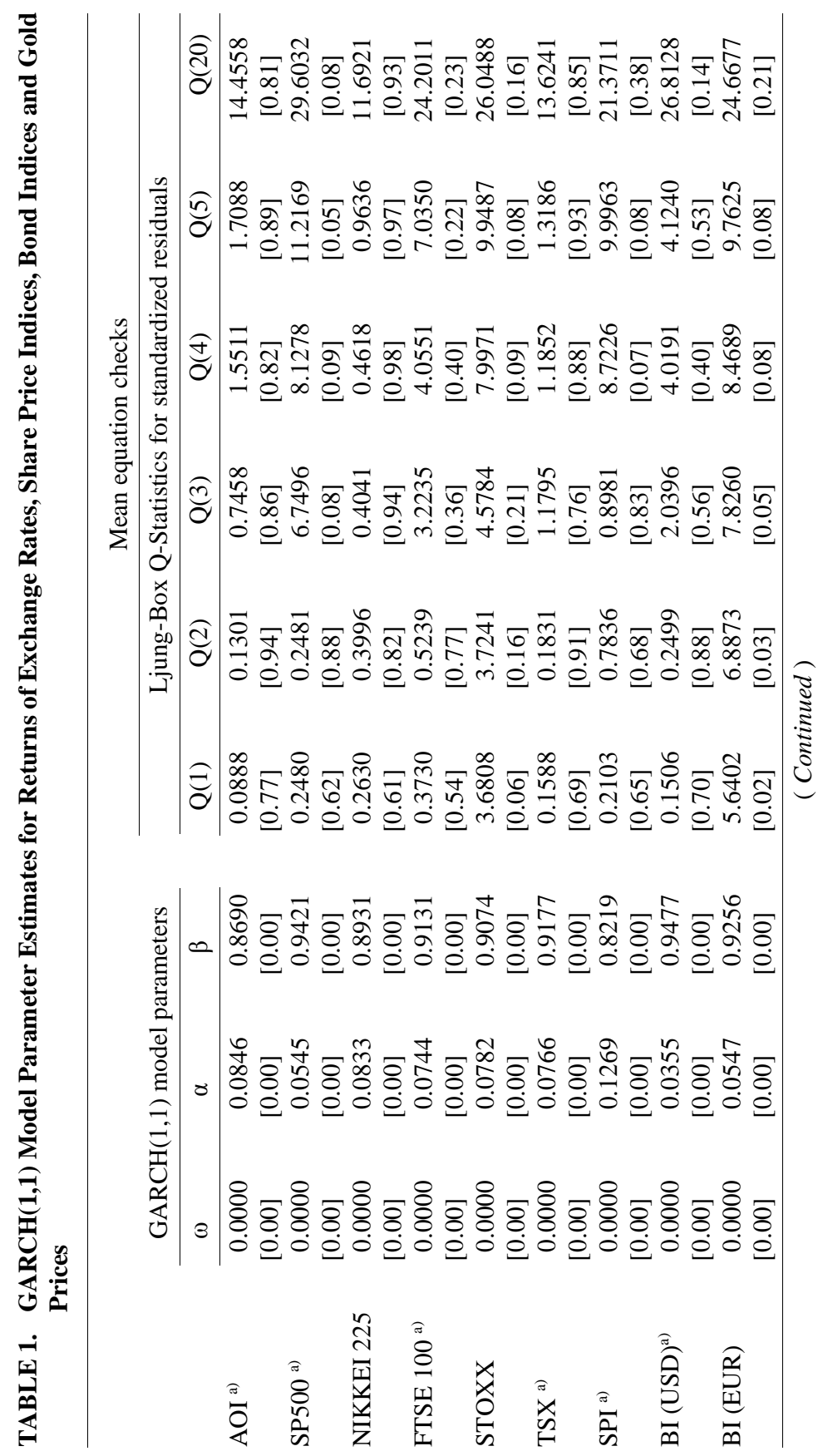




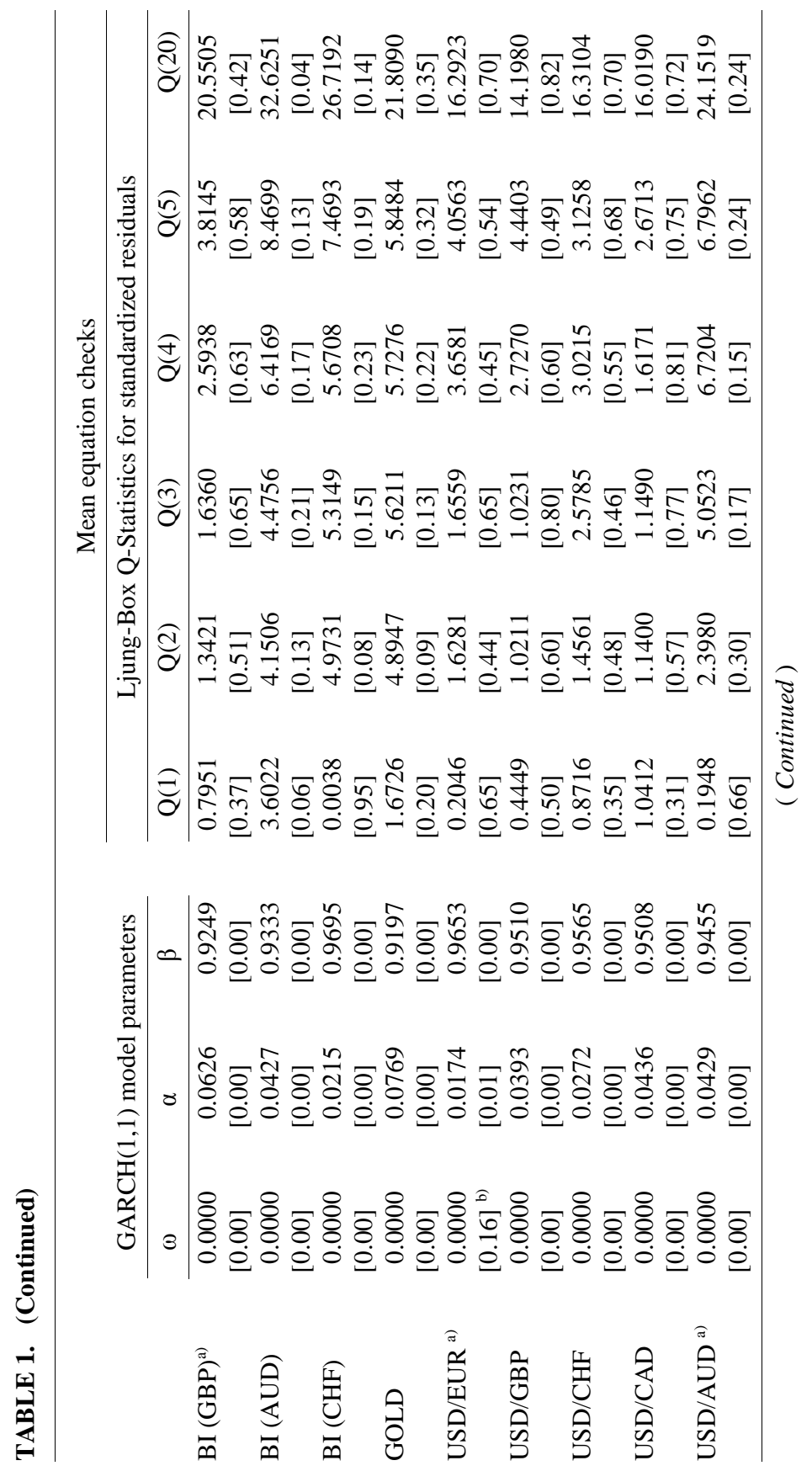




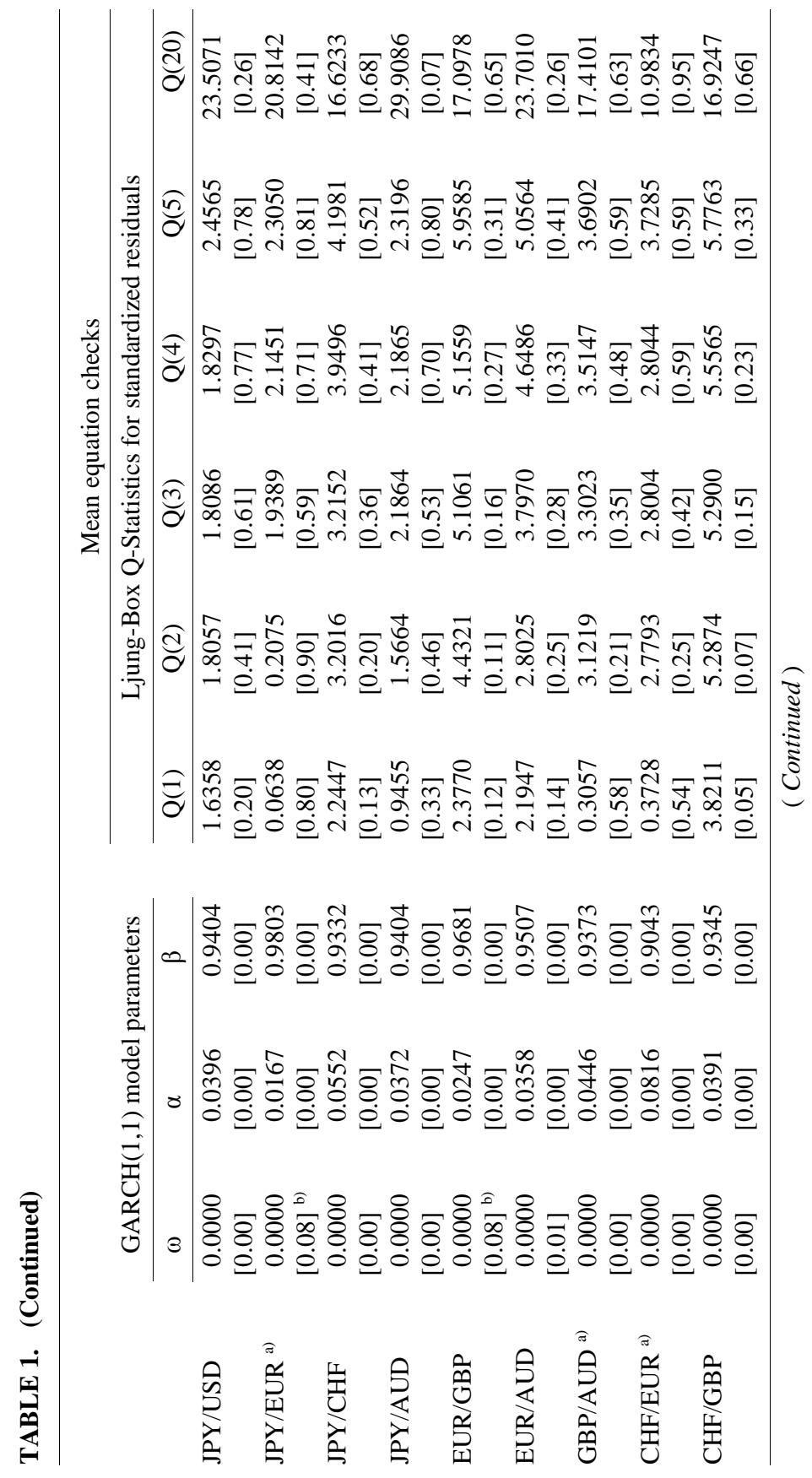




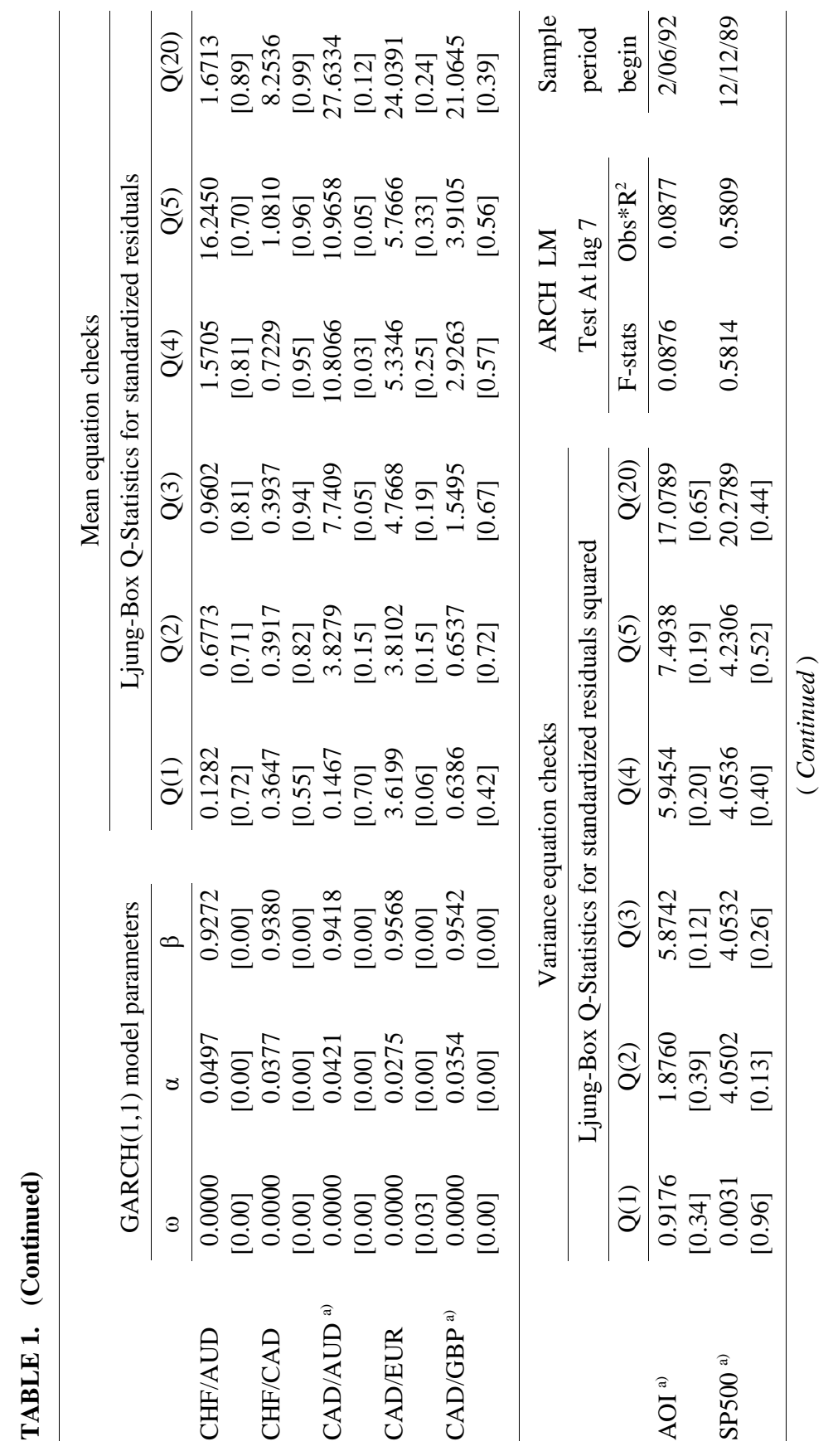




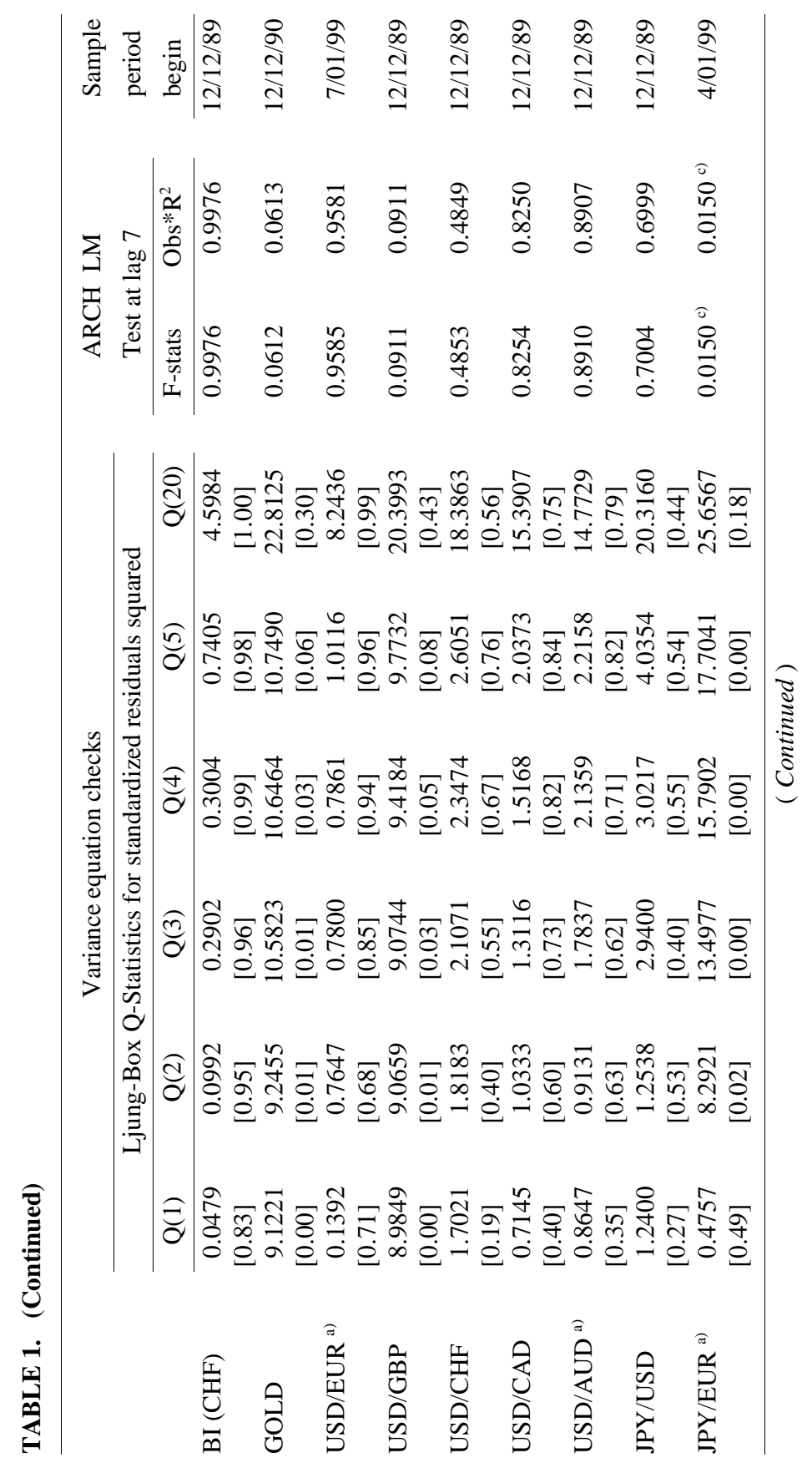


Towards Decoding Currency Volatilities

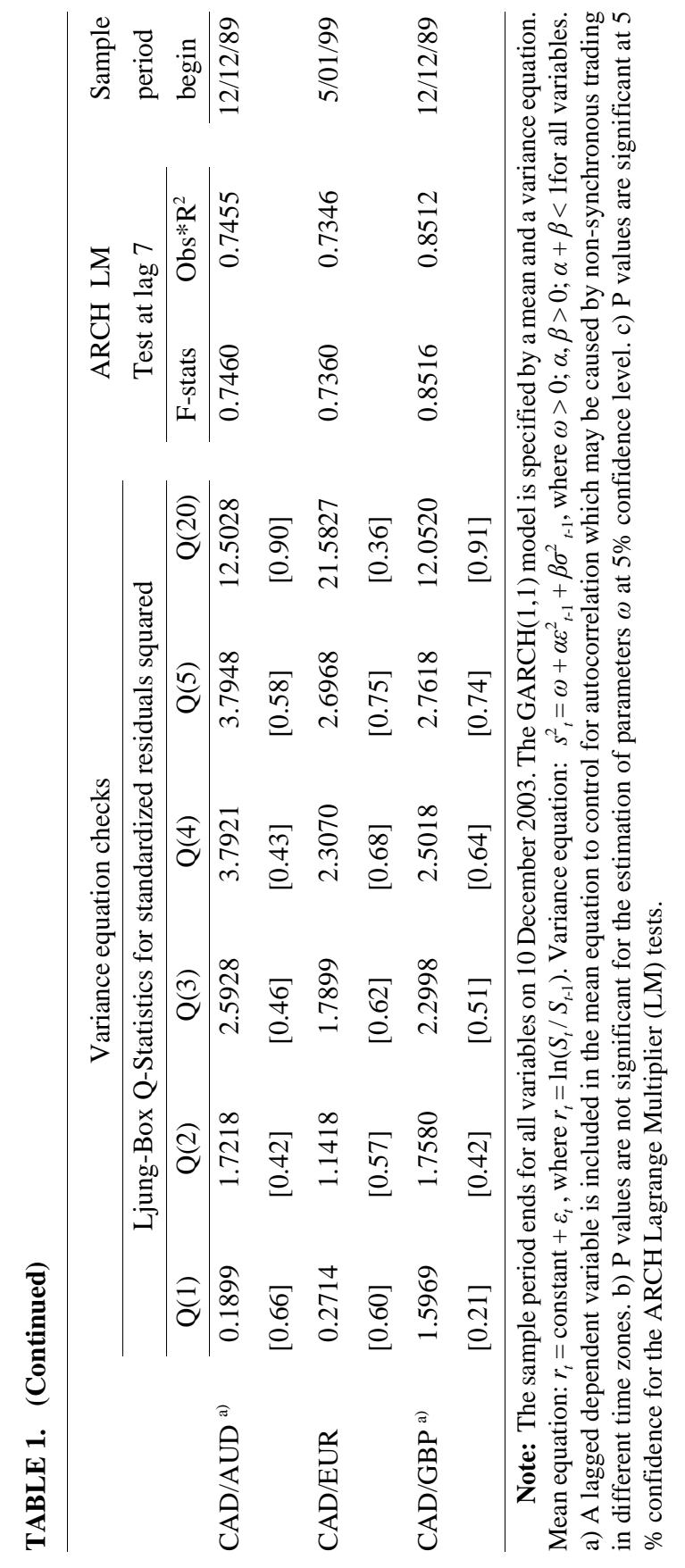


data for a period of 13 years. All data are from Thomson Datastream. ${ }^{3}$ The starting points of the sample for our study are determined by the availability of daily data for the whole set of variables used, except for gold and the British pound/Swiss franc. Due to the looming Gulf War the first differences of the volatility of the gold price showed extraordinary fluctuations. For this reason we excluded the period from the 12 December 1989 and started the sample one year later on 12 December 1990. Including in the gold sample the omitted observations would have resulted in the sum of the coefficients of (2) to exceed one, ie. $\alpha+\beta>1$. In this case the $\omega$ would have taken on a non-sensible negative value. Likewise the speculative attack on the pound in 1992 resulted in the pound leaving the European Exchange Rate Mechanism with an attendant unusually large change in the volatility of the pound sterling/Swiss franc exchange rate. This exchange rate, while not having problems with the weights, did not fit the variance equation of the $\operatorname{GARCH}(1,1)$ model. Our data for this exchange rate therefore starts on 12 December, 1992. The unique nature of the two episodes appears to justify the measure we have taken. The sample period ends for all variables on 10 December 2003.

GARCH models are estimated using maximum likelihood techniques. Table 1 contains the estimated parameter values for the mean and the variance equations for nineteen exchange rates among seven countries, their associated stock and bond indices, and for gold. The first three columns of the body of the table present the estimated parameters of equation (2). As well, diagnostic statistics for all variables of both equations are given. ${ }^{4}$

3. To check the quality of the Datastream exchange rate data, we computed for four exchange rates (US\$ $\$ \mathrm{~A}$, US $\$ / €$, $€ / £$ and $\$ \mathrm{~A} / £$ ) covered interest rate differential (Forward discount/premium - domestic/foreign interest rate differential) using daily data from January 1999 to mid-September 2003. As expected on the basis of covered interest rate parity we found for each of the exchange rates, these differences for 1, 3 and 6-month terms not to be significantly different from zero. That is, covered interest rate parity holds when Datastream data are used. The only, apparently clerical, error in the data occurred in one interest rate series. There are reasons to believe that exchange rates are less susceptible to data errors than data pertaining to share markets on which Ince and Porter (2006) focus. Data problems that the authors mention concern difficulties distinguishing between various types of securities traded on equity exchanges; stock splits; capital structure changes; ex-dividend adjustments; suspension of trading; stale prices. Trading in currencies is not afflicted by any of these complications. Similar arguments can be made with respect to share and bond indices and the gold price.

4. For details regarding the interpretation of the diagnostics see Alexander (2001, 65 $-71)$. 
The daily rate of return estimations showed autocorrelation in the residuals, perhaps due to non-synchronous trading in different time zones. In order to control for autocorrelation we included a lagged dependent variable in the mean equation. Relating the rate of return to its own lagged value in (1) means that the rate of return-constant and the residual measure the return effect conditional on the level of the most recent return. For three of our nineteen variables the p-values are not significant at the 5-percent confidence level for the estimation of the $\omega$-parameter which consists of the product of the long-run variance rate and its weight.

\section{Relationship between Exchange Rate Volatility and Volatilities of Economic Factors}

Structural exchange rate models in the mould of Meese and Rogoff (1983) include in their list of fundamental economic determinants of exchange rates domestic and foreign differentials of money supplies, GDP growth rates, inflation rates, interest rates and trade deficits. They are commonly augmented by more comprehensive portfolio balance models of exchange rate determination as developed by Branson and Henderson (1985), Bruce and Purvis (1985) and Tobin and de Macedo (1980). Portfolio balance models add domestic and foreign assets, consisting of bonds and the value of real capital, to the exchange rate determination equations. ${ }^{5}$

A standard macroeconomic exchange rate determination model in the Meese and Rogoff (1983) fashion, expanded by portfolio variables representing domestic and foreign wealth, would have the form

$$
\begin{aligned}
s_{t}= & \left(m_{t} *-m_{t}\right)+a\left(y_{t} *-y_{t}\right)+b\left(r_{t}^{*}-r_{t}\right)+c\left(p_{t}^{*}-p_{t}\right) \\
& +e\left(w_{t}^{*}-w_{t}\right)+e_{t}
\end{aligned}
$$

where $s$ measure exchange rate change, $m$ and y denote growth rates in the money supply and GDP, respectively; $r$ and $p$ stand for interest and inflations rates, respectively; $w$ denotes wealth accumulation and $e$ is a

5. For example, in Tobin and de Macedo capital is valued in current replacement costs and not expressed in current share prices. 
stochastic error term. An asterisk indicates a foreign variable. Equation (3) would only be a fitting description for the major currencies. As we are including two exchange rates with the epithet commodity currencies, we also included in the estimation equation the gold price as a proxy for the terms of trade for theses two currencies.

Now, if these macroeconomic variables drive exchange rates, their fluctuations as captured by their volatilities can also be expected to play an important role in engendering exchange rate volatility. That is, ${ }^{6}$

$$
\sigma_{i, j, t}=a+\sum_{f=1}^{n} \lambda_{f} \sigma_{f, t}+v_{t}
$$

where

$\begin{array}{ll}\sigma_{i, j} & \begin{array}{l}\text { standard deviation of the exchange rate between } i \text { and } j \\ \text { currencies }\end{array} \\ \sigma_{f} & \text { standard deviation of } f \text { economic factors } \\ v & \text { stochastic error term } \\ \lambda_{f} & \text { estimation parameter for factors } f \\ a & \text { intercept term }\end{array}$

To base our theoretical approach on the structural exchange rate model of Meese and Rogoff (1983), which performed poorly in empirical estimates, should not be regarded as an unwise choice. The microstructure view of exchange rates (eg. Lyons, 2001) with its use of high-frequency data rehabilitated the role of economic fundamentals as determinants of currency rates. Foreign exchange dealers learn from signed order flows of their customers about fundamentals and adjust exchange rates accordingly. Equation (3) provides an attempt to unravel the fundamentals that cause the order flows in the first place. However, Lyons (2001) only hypothesizes about the link of fundamentals to order flows and exchange rates. We attempt to explain volatility changes with a set of economic fundamentals in a continuous fashion on a daily basis

6. Schwert (1989) develops an analogous estimation equation for the volatility of stock returns and its relationship with the volatilities of its likely co-moving factors such as fluctuations of industrial production, inflation and stock market turnover. 
for an extended time period.

However, while economic/finance theories provide guidance as to the relevant factors and their volatilities that impact the volatility of the exchange rate, most of the required data suggested by (3) are only available on an infrequent basis, usually in monthly or quarterly intervals. We therefore have to limit the study of the volatilities of high-frequency (daily) data of exchange rates and their relationship to the volatilities of those variables in (3) that are available on a daily basis. This leaves us with only a few factors: share price and bond indices reflecting wealth as suggested by the portfolio balance approach and the gold price as a proxy for the terms of trade in the case of commodity currencies. Cross-border trading in shares, bonds and gold as well as investing in currencies as a separate asset class, say in the form of carry trades, ${ }^{7}$ appear to lend credence to our portfolio theory based hypothesis about the determinants of currency volatility changes. Our approach is predicated on the assumption that the same fundamentals that move exchange rates also matter for their volatilities.

Consequently our estimation equation is as follows

$$
\begin{aligned}
\Delta \sigma_{i, j, t}= & a_{0}+a_{1} \Delta \sigma_{i, t}^{S I}+a_{2} \Delta \sigma_{j, t}^{S I}+a_{3} \Delta \sigma_{i, t}^{B I}+a_{4} \Delta \sigma_{j, t}^{B I} \\
& +a_{5} \xi \Delta \sigma_{j, t}^{\text {Gold }}+\varepsilon_{i, j, t}
\end{aligned}
$$

where

$\sigma_{i, j} \quad$ standard deviation of exchange rate between currency $i$ and $j$

$a_{0}$ to $a_{5}$ parameters and $\varepsilon$ denotes a stochastic error term

$\sigma_{i}^{S I} \quad$ standard deviation of the relevant share price index, $\ln \left(S I_{i, t} / S I i_{i, t-1}\right)$, for countries $i$

$\sigma_{j}^{S I} \quad$ standard deviation of the relevant share price index, $\ln \left(S I_{j, t} / S I_{j, t-1}\right)$, for countries $j$

7. Currency carry trades involve the purchase of high-yielding government securities denominated in one currency financed by borrowing funds in another currency with a comparatively low interest rate. Galati and Melvin (2004) cite carry trades as one important reason for the recent surge in FX trading. 
$\sigma_{i}^{B I} \quad$ standard deviation of the relevant total return bond index, $\ln \left(B I_{i, t} / B I_{i, t-1}\right)$ for countries $i$

$\sigma_{j}^{B I} \quad$ standard deviation of the relevant total return bond index, $\ln \left(B I_{j, t} / B I_{j, t-1}\right)$ for countries $j$

$\sigma^{\text {Gold }} \quad$ standard deviation of the return on gold, $\ln \left(G_{t} / G_{t-1}\right)$ where $G$ stand for the gold price in US\$s

$\Delta \quad$ first difference operator

$\xi=1$ for the exchange rates involving the Australian or Canadian dollar

$\xi=0 \quad$ for all other exchange rates

We use first differences of the respective standard deviations in order to induce stationarity in the volatility variables.

\section{A. Explanatory Variables}

What is the rationale behind the inclusion of the volatilities of the five variable on the right hand side of equation (5), namely domestic and foreign share and bond price indices and gold? We commence our discussion with the two wealth variables.

Wealth: In the portfolio balance model asset demand equations are homogeneous of degree one in wealth, implying a doubling of assets demands when wealth doubles. ${ }^{8}$

According to the portfolio balance approach of modelling the financial sector, an increase in wealth of an economic agent, and by analogy of a country, will increase the demand of individuals and countries for securities (bonds and shares). The share indices are assumed to capture part of these asset demand effects. In addition, asset demands depend on expected domestic and exchange rate adjusted foreign rates of return (see Tobin and de Macedo, 1980). The 'new economy' sectors of the global economy with their often inflated

8. Tryon (1983) provides a survey of the portfolio balance approach to exchange rate determination. 
expected rates of return would have undoubtedly benefited in terms of attracting capital inflows and thus contributed to share price index volatility. The share price indices are assumed to proxy for the wealth of a country. The indices for the seven countries included are: Australian All Ordinaries share price index AOI, the Standard\&Poor's 500 Price Index (S\&P500), the Nikkei225 Index (NIKKEI), the London Stock Exchange index (FTSE100), Dow Jones Euro Stoxx 50 Index $(\operatorname{Stoxx})^{9}$, the Toronto Stock Exchange (TSX) index and the Swiss Performance Index (SPI, Price Index Version).

Logic requires that we include in bilateral exchange rates both respective share price indices in the estimation equation (5) as capital flows in both directions. However, since even the first differences of share price index volatility show significant correlations - in the case of the Swiss Share Price Index (SPI) and the Stoxx index the correlation has an amazing $\rho=0.7-$ we included only the dominant index in the estimation equation under such circumstances.

We also incorporate bond indices in our estimation equation as international bond investors may also hold part of their wealth in bonds. ${ }^{10}$ As bonds in general are imperfect substitutes for each other in global financial markets and by assumption in portfolio balance models, relative bond supplies/demands will affect exchange rates. Even though the countries we include in our sample are of the highest credit standing, their rates of return may differ due to non-synchronous business cycles. We therefore include the first differences of both bond indices in our regression equation relating first differences to the volatility of their corresponding exchange rate. For example, we would include both the volatility change of the US and the Australian bond indices in the equation of the US\$/\$A exchange rate. However, bond index volatility correlations - the UK and the European first differences of the volatilities of bond indices showed high correlation $(\rho=0.604)$ - forced us to discard one and retained the index of the dominant IBOXX Euro Bond Index 3 - 5 years. Moreover, failure to fit the GARCH-equation to the Japanese and Canadian bond indices forced us to exclude both

9. The Dow Jones Euro Stoxx 50 is a euro area-specific stock index. Even though it is narrowly based it has a correlation with the much broader pan European based MSCI Europe of $97 \%$ between January 1999 and 30 September 2003. Moreover, in contrast to the US experience where stock index trading focuses on the broad-based S\&P500, the Euro Stoxx 50 is the most actively traded contract on European exchanges (Bank for International Settlements, December 2003). The index is therefore representative beyond its size and in trading activity.

10. The global share and bond markets are of about equal size. 
from the sample. In estimates of the volatilities of both currencies we employ the bond indices of the respective companion currencies. Information about the bond indices is as follows:

\section{B. Government Bond Indices}

US Benchmark 5 Year DS Govt. Index - Total Return Index $12 / 12 / 89$ to $10 / 12 / 03$

IBOXX EURO Bond Index, 3 - 5 Years: - Total Return Index $01 / 01 / 99$ to $10 / 12 / 03$

UK Benchmark 5 Year Govt. Index - Total return Index $12 / 12 / 89$ to $10 / 12 / 03$

AUS Benchmark 5 Year DS Govt. Index - Total return Index $12 / 12 / 89$ to $10 / 12 / 03$

Swiss Benchmark 5 Year DS Govt. Index - Total return Index $12 / 12 / 89$ to $10 / 12 / 03$

Gold Price: Some exchange rate determination models include the terms of trade amongst the explanatory variables. ${ }^{11}$ Since daily data of terms of trade are unavailable, we have selected the volatility of gold as a proxy for the terms of trade. We include the first differences of the gold price volatility in estimation equations involving the Canadian and Australian dollars.

\section{Descriptive Statistics}

All time series data of first differences of daily standard deviations are generated by a GARCH $(1,1)$ procedure for returns on foreign exchange rates, share price indices and on the gold price. The sample size refers to first differences of daily standard deviations.

Table 2 presents the pair wise correlations coefficients of first differences of the standard deviations of the variables. As one would have expected sizeable correlation values are virtually non-existent for most of the first differences of standard deviations of the variables. The

11. The Canadian-US\$ real exchange rate is linked by Amano and Norden (1995) to the terms of trade and Gruen and Wilkinson (1994) explore the relationship between the US\$-\$A exchange rate and the terms of trade. 
exceptions are the share price indices; to our surprise we register a correlation coefficient of as high as $\rho=0.706$ between the STOXX and the SPI. The second highest correlation is between the STOXX and the FTSE. As mentioned, these high co-movements have been taken into account in the estimation design. As a consequence of the high correlation coefficients between some share indices, we omitted one of them in our estimation of (5). As a general rule we retained the share index presenting the larger market of the two pairs of indices.

Before reporting our estimation results, we investigate two further properties of our sample. First, we carried out ADF-tests for unit roots of the levels of the standard deviations and of their first differences. On the basis of the test results only in the case of two (of the levels) of exchange rate volatilities were we not able to reject the hypothesis of unit roots. As for the first differences of the volatilities, none of our variables actually used in the test equations has unit-root features, that is, they are stationary. A second preliminary issue concerns the causality embedded in the test equation. In order to obtain a clearer picture about the relationship between the variables on both side of equation (5), we apply a Granger-causality test. ${ }^{12}$ The evidence points in the great majority of equations to a causal link running from share and bond indices to exchange rates for 1-day and 10-day lags. For the first differences of gold price volatilities no clear directional relationship emerged. Thus the results pertaining to this variable portray a relationship rather than a causal linkage, between both sides of the equation. ${ }^{13}$ However, the inconclusiveness of the causality test for gold does not rule out that expected gold price and associated volatility changes clearly engender exchange rate adjustments.

\section{Estimation Results}

The results for the estimation equation (5) are presented in table 3. The

12. A Granger causality test ascertains how much of current time series can be explained by its own past values and whether adding lagged values of another time series can improve the explanation. The Granger causality results are available from the corresponding author.

13. It is worthwhile emphasizing the fact most volatility studies involving exchange rates encounter similar problems which is most pronounced in intervention investigations. The question 'Do central banks intervene at times because currency markets are disorderly or does intervention provide a fillip to volatility?' remains largely unanswered. 


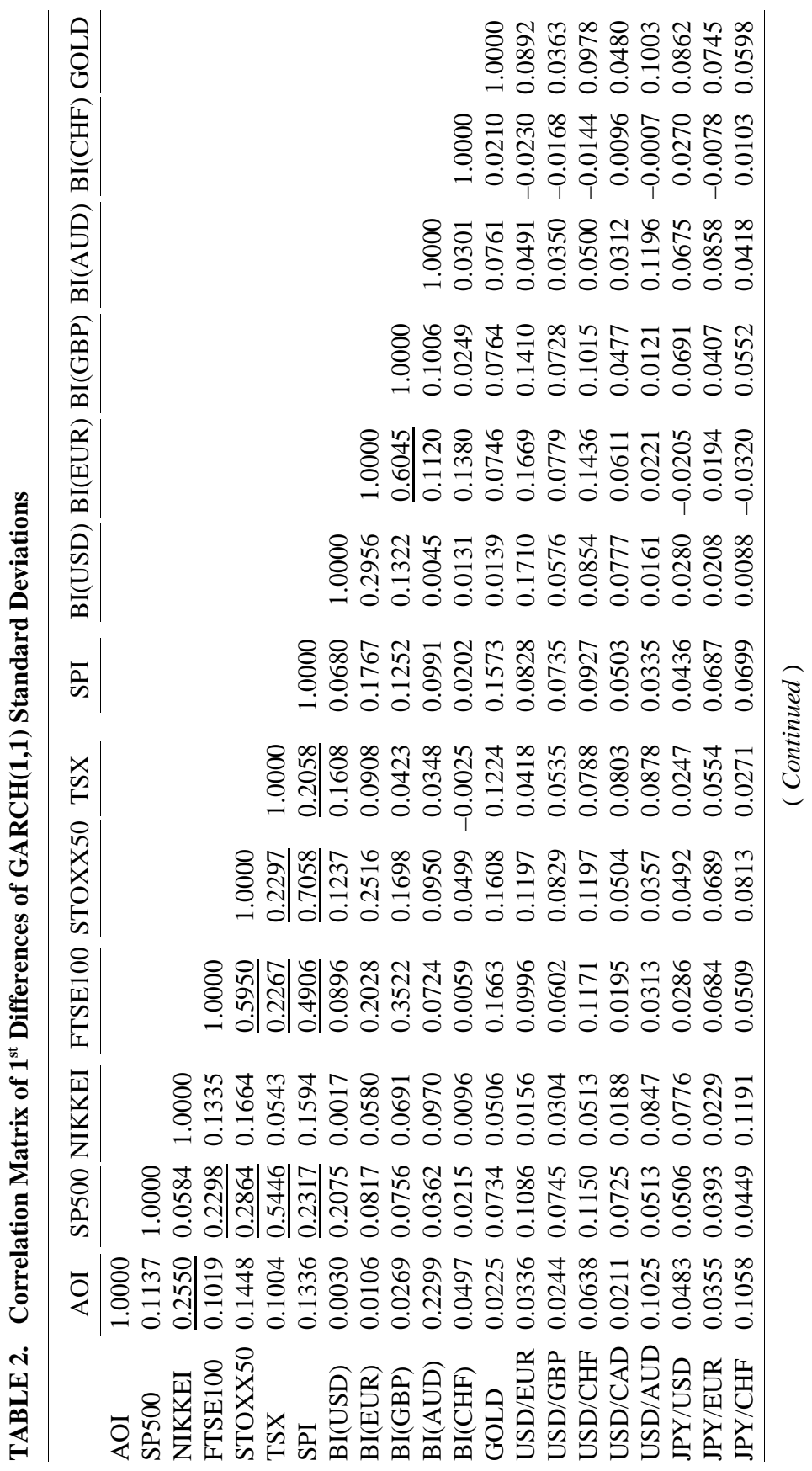




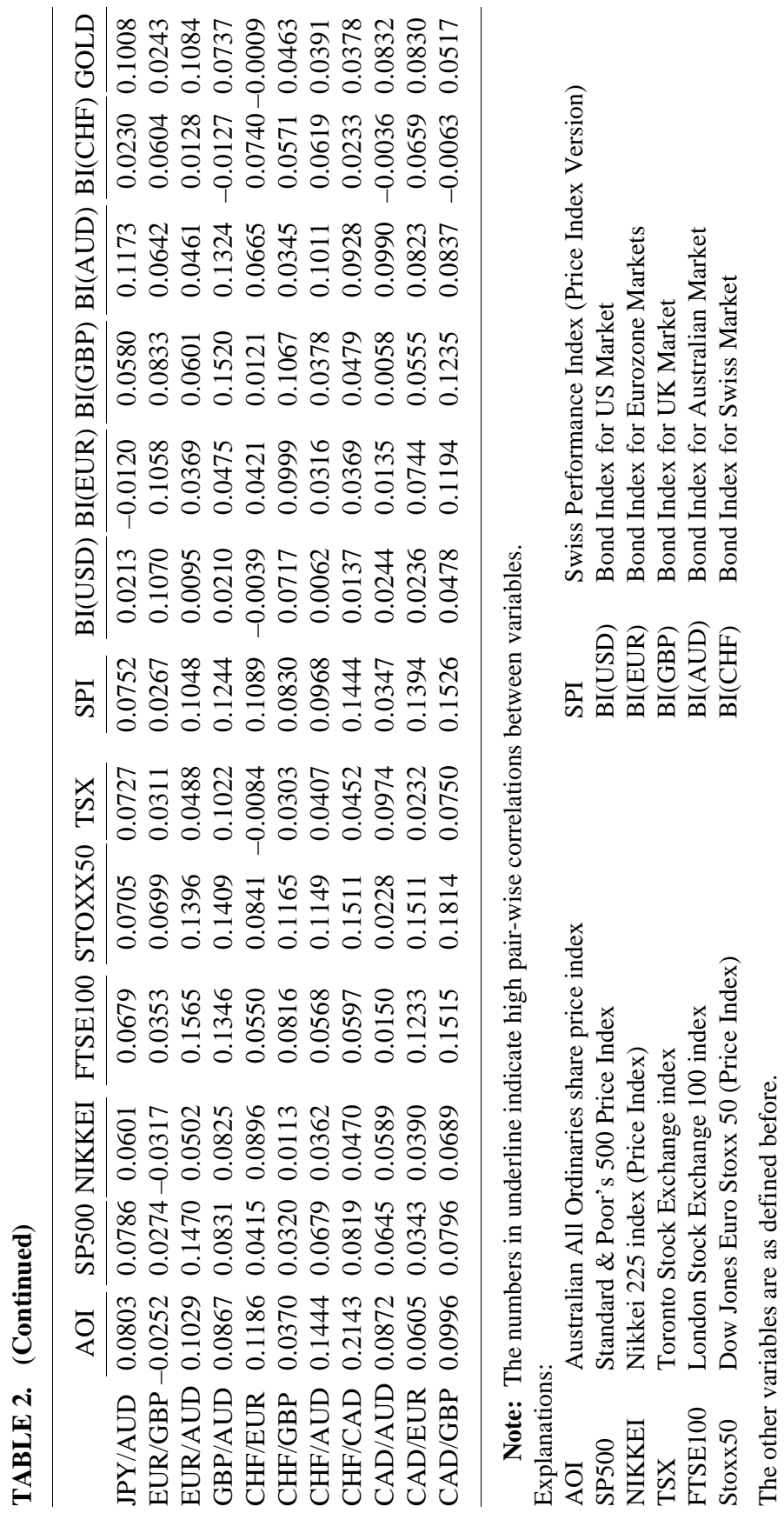




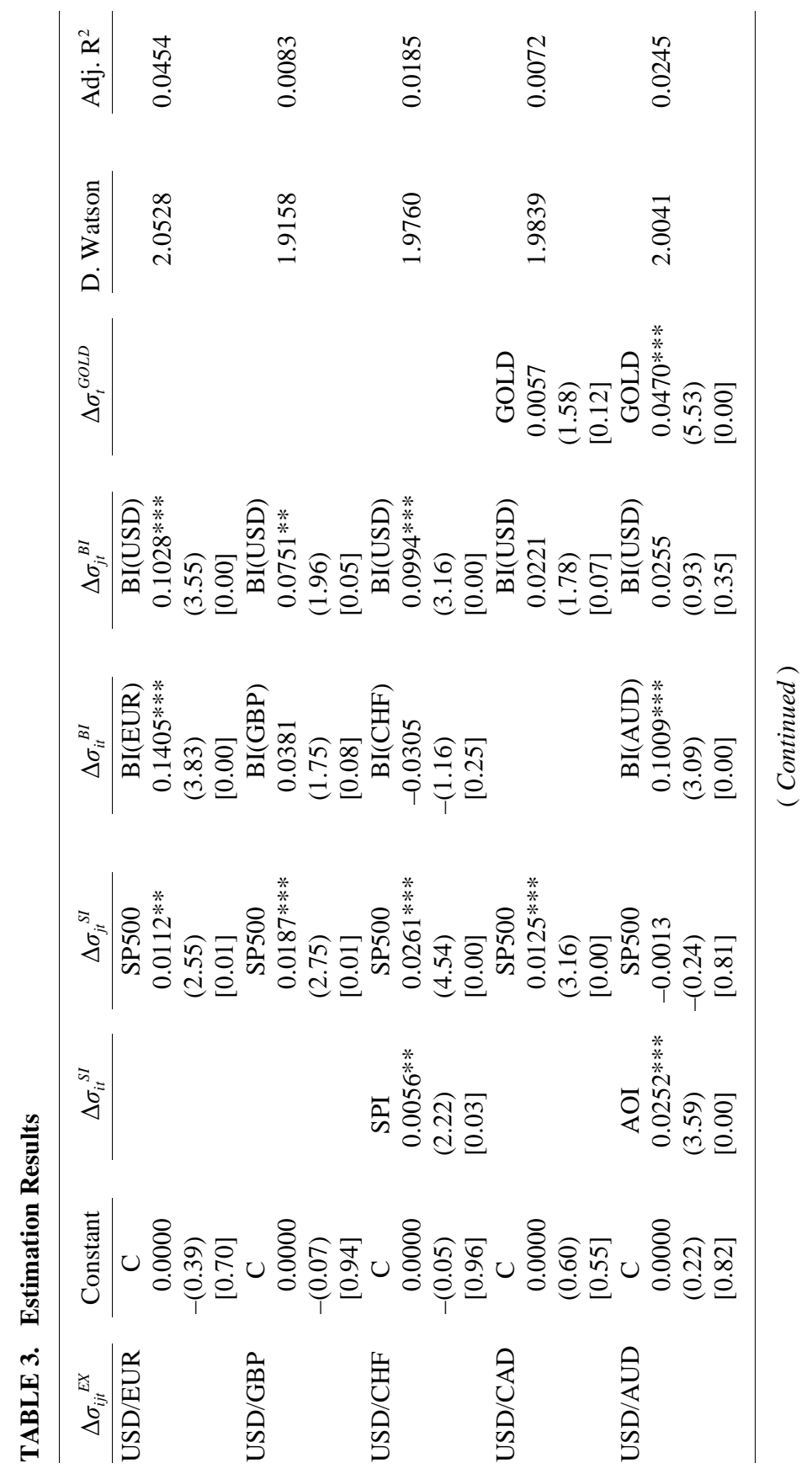


Towards Decoding Currency Volatilities

127

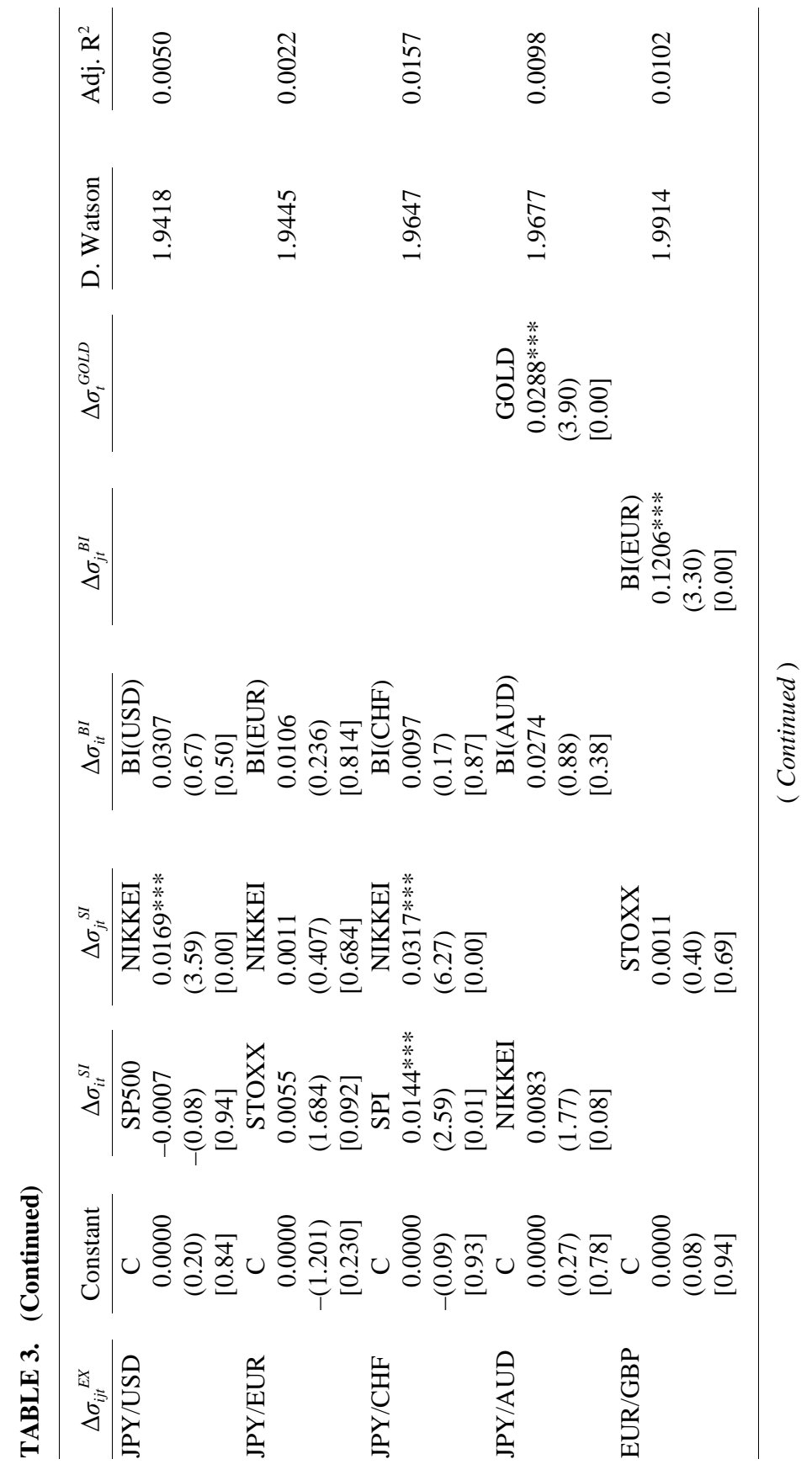




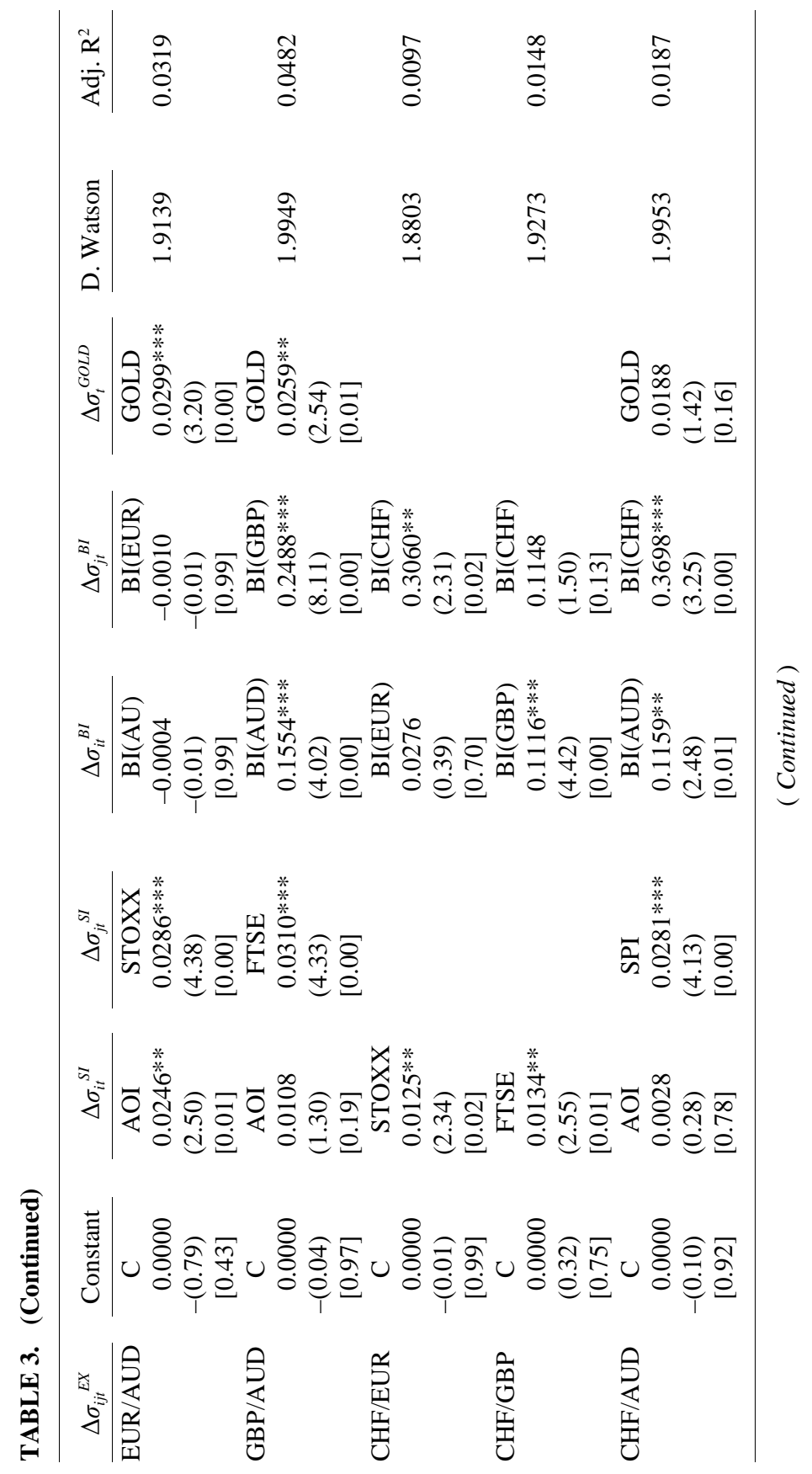




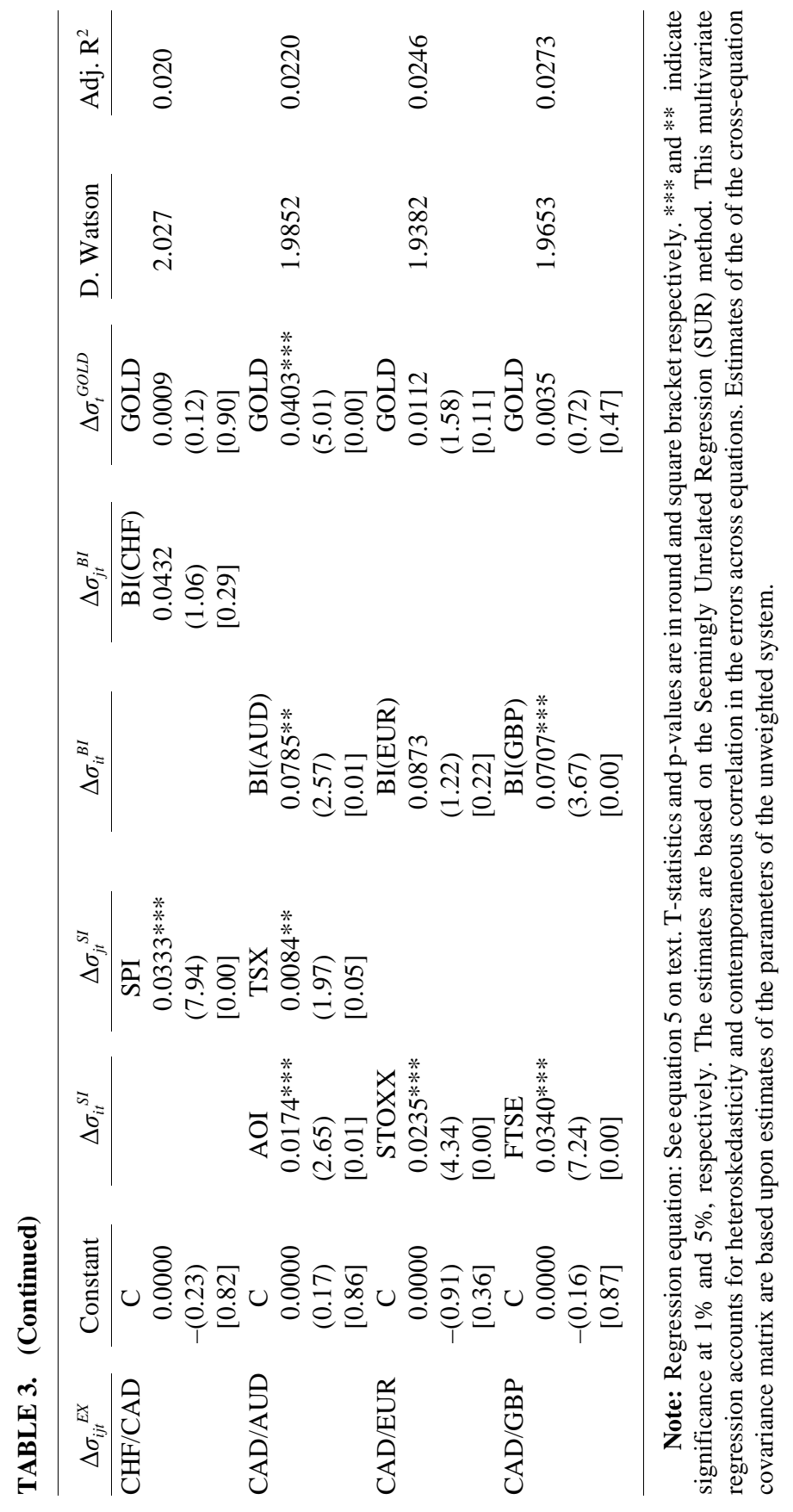


estimates are based on the Seemingly Unrelated Regression (SUR) method. This multivariate regression accounts for heteroskedasticity and contemporaneous correlation in the errors across equations. Estimates of the cross-equation covariance matrix are based upon estimates of the parameters of the unweighted system. The Durbin-Watson statistics suggest that no autocorrelation of the residuals exists. The size of the coefficients of determination of adjusted $\mathrm{R}^{2}$ is consistent with those achieved by similar studies that use first differences of daily data.

Considering the extent to which exchange rates fluctuate on a daily basis, we were surprised to find what appear to be some systematic links between changes in exchange rate volatility and a well defined set of first differences of volatility factors. Take, for example, the volatility equation of the US\$/€ in the first row of table 3. The change in the currency volatility depends positively on the change of the share market volatility as well as the European and US bond index volatilities. Thus greater uncertainty in share and bond markets works its way through cross-border global portfolio adjustments, the removal or imposition of currency hedges and the assuming or abandoning of currency positions into heightened currency fluctuations. The reverse process occurs in the case of a subsidence of share and bond price fluctuations. Meaningful results were also achieved with the inclusion of the gold price volatility for the Canadian and Australian dollars commodity currencies.

Overall, the estimation results provide strong support for our model which attempts to explain the first differences in the volatilities of our final sample of 19 currencies. With the exception of two (that were insignificant), all of the 28 coefficients of the share price indices exhibit, as expected, positive signs. The vast majority of the coefficients are significant at the 5\%-level or better. The volatility changes of the share price indices appear to proxy mainly for the uncertainties associated with portfolio adjustments as postulated by the portfolio balance model. We also experimented with total return share indices and achieved remarkably similar results.

An analogous picture emerges for the impact of changing bond market volatilities on currency fluctuations. A total of 14 of the 28 bond indices are significant at least at the 5\% significance level. Only two indices showed negative signs though the coefficients were insignificant. We chose the bond total return indices as a pendant to the share indices as both markets are of the same size on a global basis and presumably of similar importance for wealth management.

Of the ten equations involving commodity currencies, five 
coefficients of the acceleration in gold price volatility are statistically significant at the postulated level and all have the expected positive signs. When we included the first differences of gold volatility in the remaining exchange rate equations involving non-commodity currencies, none turned out to be significant as was to be expected. For example, premier service and high-technology economies such as the UK, Switzerland, Europe or the US are unlikely to experience a systematic impact of terms of trade changes on their exchange rates and their volatilities. This negative outcome appears to validate the inclusion of the gold price volatility only in the two commodity currencies.

\section{Conclusions}

Apart from announcement effects pertaining to information releases and official interventions in the event-study mode, no systematic and detailed analyses have been carried out into explaining the changes in currency volatility in terms of its presumed economic determinants, using high-frequency data. In addition, the number of currencies in extant intervention-volatility studies as well as announcement papers can easily be counted on the fingers of one hand. This time series study is the first to tackle the relationship between changes in exchange rate volatilities of major and several minor currencies and changes in the volatilities of their presumed major economic determinants. For the selection of factors that can be expected to influence or are related to, exchange rate volatility, we are guided by economic theory. The use of daily data restricts our choice to a portfolio balance model where global asset reshuffling impact on exchange rates. We postulate that a parallel and plausible relationship exists between changes in volatilities of currencies and the volatilities of their determinants. The empirical estimates link domestic and foreign volatilities of share price indices as well as the volatilities of pair-wise changes of bond performance indices to currency volatilities for 19 currencies. For the so-called commodity currencies such as the Australian and the Canadian dollar their volatilities in addition depend on the volatility of the gold price. The sample consists of daily $\operatorname{GARCH}(1,1)$ volatilities of the set of variables for varying periods from mid-December 1989 to 10 December 2003. The volatility variables used are computed as first differences which are based on continuously compounded rates of return. A surprisingly large 
proportion of the coefficients of the share and bond indices are significant at the commonly accepted levels. The same applies to the first difference of the gold price volatility for the exchange rates involving the Australian and Canadian dollars. The Durbin-Watson test statistics suggest the absence of autocorrelation in the residuals. The coefficients of determination have comparable values to those in studies that use first differences of volatilities. The results of our study enhance our understanding of high-frequency currency volatility changes beyond the insights of announcement effect studies.

Do any policy prescriptions or other useful implications flow from our study? It appears our test results contribute towards deciphering the enigma of daily changes of volatilities of exchange rates and their presumed associated fundamental economic determinants over a comparatively long time horizon. More than anything else, the study highlights that volatility changes in currency markets do not appear to occur in isolation. In general the level of trading activities in share and bond markets, and for commodity currencies turnover in the gold market, contribute to an explanation of currency volatilities.

Financial risk managers, portfolio investors and traders are likely to benefit from the outcomes of our approach to explain accelerations of currency volatilities. Changes in share, bond and gold market volatilities may provide early warning signals regarding expected changes in currency volatilities. Banks and regulators could benefit in their calibrations of the daily value-at-risk management tasks. Likewise, short-term portfolio reshuffling in anticipation of increased risk resulting from impending currency risk could be implemented earlier. Options traders may gain valuable information from the behaviour of volatilities in related markets for the valuation of currency options in the very short-term.

Accepted by: Prof. R. Taffler, Guest Editor, February 2009

Prof. P. Theodossiou, Editor-in-Chief, February 2009

\section{References}

Alexander, C. 2001. Market Models - A Guide to Financial Data Analysis. Chichester: John Wiley.

Amano, R., and S. van Norden, S. 1995. Terms of trade and real exchange rates. Journal of International Money and Finance 14: 83 - 104.

Anderson, T.G., and Bollerslev, T. 1998. Deutschemark-dollar volatility: Intraday activity patterns, macroeconomic announcement, and longer run 
dependencies. Journal of Finance 53: 219 - 266.

Andersen, T.; Bollerslev, T.; Diebold, F.; and Vega, C. 2003. Micro effects and macro announcements: real-time price discovery in foreign exchange. American Economic Review 93: 38 - 62.

Bank for International Settlements, 2003. The Rise of Pan-European Equity Index Trading, Basel: Bank for International Settlements Quarterly Review. December: 44.

Bank for International Settlements, 2002. Triannual Central Bank Survey of Foreign Exchange and Derivatives Market Activity. Basel: Bank for International Settlements.

Bayoumi, T., and Eichengreen, B. 1998. Exchange rate volatility and intervention: Implications of the theory of optimum currency areas. Journal of International Economics. 45: 191 - 209.

Bonser-Neal, C., and Tanner, G. 1996. Central bank intervention and the volatility of foreign exchange markets: Evidence from the options markets. Journal of International Money and Finance.15, 853 - 878.

Branson, W., and Henderson, D. 1985. The specification and influence of asset markets. In R. Jones and P. Kenen, (eds). Handbook of International Economics, Vol 2, 749. - 805, Amsterdam: North-Holland.

Bruce, N., and Purvis, D. 1985. The Specification and Influence of Goods and Factor Markets in Open-Economy Macroeconomic Models, in R. Jones and P. Kenen, (eds). Handbook of International Economics, Vol 2, 807 - 857, Amsterdam: North-Holland.

DeGennaro, R., and Shrieves, R. 1997. Public information releases, private information arrival and the volatility in the foreign exchange market. Journal of Empirical Finance. 4: 295 - 315.

Devereux, M. B., and Lane, P. R. 2003. Understanding Bilateral Exchange Rate Volatility, Journal of International Economics. 60: 109 - 132.

Dominguez, K., and Panthaki, F. 2006. What defines 'News' in foreign exchange rates? Journal of International Money and Finance. 25: 168 198.

Dominguez, K. 1998. Central bank intervention and exchange rate volatility. Journal of International Money and Finance. 17: 161 - 190.

Ederington, L.H., and Lee, J.H. 1996. The creation and resolution of market uncertainty: The impact of information releases on implied volatility. Journal of Financial and Quantitative Analysis. 31 (December): 513 - 539.

Galati, G., and Melvin, M. 2004. Why has FX trading surged? Explaining the 2004 Triennial Survey. Bank for International Settlements. Quarterly Review (December): 67 - 74.

Gruen, D., and Wilkinson, J. 1994. Australia's real exchange rate - Is it explained by the terms of trade or by real interest rate differentials? Economic Record 70: 204 - 219.

Hung, J. 1997. Intervention strategies and exchange rate volatility: A noise trading perspective. Journal of International Money and Finance.16: 779 
$-793$.

Ince, O., and Porter, P. 2006, Individual equity return data from Thomson datastream: Handle with care! Journal of Financial Research. 29: (Winter): $463-479$.

Jansen, D.J., and De Haan, J. 2005. Talking heads: The effects of ECB statements on the euro-dollar exchange rate. Journal of International Money and Finance. 24: 343 - 361.

Jorion, P. 1995. Predicting volatility in the foreign exchange market. Journal of Finance. 50 (June): 507 - 528.

Kim, M., and M. Kim, M. 2003. Implied volatility dynamics in the foreign exchange markets, Journal of International Money and Finance. 22: 511 528.

Kim, S.; Kortian. T; and J. Sheen, J. 2000. Central bank intervention and exchange rate volatility - Australian evidence. Journal of International Financial Markets, Institutions and Money. 10: 381405.

Lyons, R. K. 2001. The Microstructure Approach to Exchange Rates, Cambridge Mass.: MIT Press.

Meese, R. and Rogoff, K. 1983. Empirical exchange rate models of the seventies. Journal of International Economics. 14: 3 - 24.

Schwert, G.W. 1989. Why does stock market volatility change over time? Journal of Finance. 54 (December): 1115 - 1153.

Tobin, J., and de Macedo, J. 1980. The short-run macroeconomics of floating exchange rates: An exposition, in: J. Chipman and C. Kindleberger, (eds). Flexible Exchange Rates and the Balance of Payments. 5-28. Amsterdam: North Holland.

Tryon, R.W.1983. Small empirical models of exchange market intervention: A review of the literature, Staff Studies, 134, Board of Governors of the Federal Reserve System, September. 